\title{
Effect of Source-Substrate Distance on Transparent Electrode Properties of the Spray-Cast Aluminium Doped Zinc Oxide Thin Films
}

\section{Sebin Devasia}

Universidad Autónoma de Nuevo León: Universidad Autonoma de Nuevo Leon

\section{P V Athma}

Union Christian College

Rakhy Raphael

Union Christian College

Anumol Jose

Union Christian College

Anila E I ( $\square$ anilaei@gmail.com )

Christ University https://orcid.org/0000-0002-7975-3659

\section{Research Article}

Keywords: Zinc oxide, thin films, spray pyrolysis, Aluminium doping, transmittance, Hall-effect measurements

Posted Date: February 17th, 2021

DOI: https://doi.org/10.21203/rs.3.rs-230292/v1

License: (c) (1) This work is licensed under a Creative Commons Attribution 4.0 International License. Read Full License 


\title{
Effect of Source-Substrate Distance on Transparent Electrode Properties of the Spray-Cast Aluminium Doped Zinc Oxide Thin Films.
}

\author{
Sebin Devasia ${ }^{1,2}$, P V Athma ${ }^{2,3}$, Rakhy Raphael $^{2}$, Anumol Jose ${ }^{4}$ and E I Anila ${ }^{2,5, *}$ \\ ${ }^{1}$ Facultad de Ingeniería Mecánica y Eléctrica, Universidad Autónoma de Nuevo León. San Nicolás de los \\ Garza, Nuevo León, México, 66455 \\ ${ }^{2}$ Optoelectronic and Nanomaterials' Research Lab, Department of Physics, Union Christian College \\ Aluva, Kerala, India -683102 \\ ${ }^{3}$ Department of Physics, SNM College Maliankara, Kerala, India -683 516 \\ ${ }^{4}$ Department of Botany, U C College, Aluva, Kerala, India-683102 \\ ${ }^{5}$ Department of Physics and Electronics, CHRIST (Deemed to be University), Bengaluru-560029
}

\begin{abstract}
The wide band gap zinc oxide is a potential metal oxide that has been widely used in optoelectronic applications. The zinc oxide thin films demonstrates excellent conductivity and transparency enabling them for transparent electrode applications. The aluminium doping is an efficient route in further improving the conductivity without compromising the transparency and scalable spray pyrolysis is an effective approach in realizing high quality thin films. Our current study focuses on the effects of distance between the substrate and spray nozzle on the structural, morphological, optical, and electrical properties of aluminium doped zinc oxide. Our results suggests that this spray parameter has appreciable impact on the thin film properties and can be optimized for tuning properties. We explain this in detail backed by the characterization of thin films by X-ray diffraction, Atomic Force Microscopy, UV-Vis-NIR spectroscopy, Photoluminescence and Hall effect measurements.
\end{abstract}

Keywords: Zinc oxide, thin films, spray pyrolysis, Aluminium doping, transmittance, Hall-effect measurements.

*Email:anilaei@gmail.com

\section{Introduction}

Zinc oxide $(\mathrm{ZnO})$ is a direct and wide bandgap $(\sim 3.37 \mathrm{eV}$ at room temperature $)$ semiconductor which has gained considerable attention as an important technological material having short wavelength optoelectronic applications such as LEDs[1], photodetectors[2] and laser diodes[3,4]. Interestingly $\mathrm{ZnO}$ is conductive despite its transparency to visible light which can be further enhanced by doping with suitable elements[5-7]. The intrinsic n-type characteristics can be improved upon doping with group III elements such as In, Ga, B and Al as well as $\mathrm{F}$ and H[4]. Particularly, Al doping has shown to be highly suitable considering their ionic radii, inexpensive and easy to handle dopant sources and $\mathrm{AZO}$ (Al-doped $\mathrm{ZnO}$ ) thin films had enhanced transmittance in addition to the increased carrier concentration and 
conductivity[6]. Highly efficient Al doped $\mathrm{ZnO}$ based Solar cells[6], LEDs [8], Transistors [9] etc. have been realized. Especially, AZO films have comparable optoelectronic properties as that of widely used $\mathrm{TiO}_{2}$ layer which suffers from degradation under UV-irradiation and low electron mobilities[10,11].

AZO thin films can be fabricated through various deposition techniques like rf magnetron sputtering [12], chemical vapour deposition [13], molecular beam epitaxy [14], pulsed laser deposition [15], sol-gel [16], electrodeposition [17] and chemical spray pyrolysis (CSP). Among these widely reported techniques, spray pyrolysis is a versatile method that offers a wide range of parameter space which can be interplayed in extending the range of photophysical properties of thin films. Moreover, it is a truly scalable technique that can be modified for cost-effective large area deposition in the industrial production of optoelectronic devices [18].

The properties of the thin films developed by spray pyrolysis are affected by several factors like substrate temperature, solution flow rate, deposition time, atomization pressure, sourcesubstrate distance, size and distribution of the droplets, solvent properties, nature of substrate surface and precursor composition. By controlling these factors one can tailor various properties of the deposited film for specific applications[6]. Therefore, detailed studies are required in understanding the effects of all these parameters and their correlation for further optimization and application.

In the chemical spray pyrolysis technique, the droplets created by breaking the precursor solution at the nozzle using compressed air are carried to the heated substrate surface where it spread and react to initiate nucleation and further crystallization. During the droplet transport in aerosol, it undergoes interactions with the spray atmosphere and the solvent vapor as well as among themselves by the exchange of heat and energy. This may lead to spreading, receding or amalgamation of droplets [19]. There are different models like the Langmuir-Knudsen formulations or the evaporation of water droplets containing dissolved or suspended solids, that can explain the volatilization process during the droplet flight [20,21]. These models suggests that the momentum transfer between the droplet and carrier gas is a function of drag force and the energy exchange is through a convective heat transfer. Further, various forces coming into play during the transport are gravitational, thermophoretic, stokes and electric forces. In the case of large droplets $(>2 \mu \mathrm{m})$, the thermophoretic force is developed due to the temperature gradient which will push the droplets away from the substrate surface[22]. At the same time, the droplets 
moving down through this temperature gradient can undergo evaporation in flight which may lead to a concentration gradient resulting in surface precipitation upon exceeding the solubility limit. Consequently, the thin films obtained will be powdery and will have high roughness.

All these processes involved during droplet transport is related to precursor concentration, droplet size, spray rate and most importantly, the nozzle to substrate distance. In fact, the nozzle to substrate distance is so important that it determines the length of droplet interactions before reaching the substrate surface. Hence, we examine the influence of distance between the spray nozzle and the substrate surface (source-substrate distance) on the structural, morphological, electrical, and optical properties of $\mathrm{Al}$ doped $\mathrm{ZnO}$ films developed by CSP technique.

\section{Experimental details}

Al-doped $\mathrm{ZnO}(\mathrm{AZO})$ thin films were deposited on soda-lime glass substrates using CSP technique. Initially, the substrates were cleaned using soap solution, chromic acid for 2 hours and then ultrasonically cleaned in distilled water and acetone. The $0.2 \mathrm{M}$ precursor solution was prepared by dissolving zinc acetate $\left(\mathrm{Zn}\left(\mathrm{CH}_{3} \mathrm{COO}\right)_{2} .2 \mathrm{H}_{2} \mathrm{O}\right.$, Sigma-Aldrich, 99.5\%) and aluminium chloride $\left(\mathrm{AlCl}_{3}, \mathrm{MERCK}, \geq 98 \%\right)$, the host material and dopant source, respectively, in the solvent mixture of propanol and deionized water (7:3). Molarity of the spray solution was fixed at with an aluminium concentration of 2 at.\%. $3 \mathrm{ml}$ acetic acid was added to the aqueous solution to prevent the formation of hydroxides. Pressure of the gas fed into the nozzle has to be measured using the mechanical gauge and the pressure was fixed at 1bar. The prepared solution was sprayed for 10 minutes at a spray rate of $6 \mathrm{ml} /$ minute, onto the glass substrate kept at a temperature of $450^{\circ} \mathrm{C}$. The source-substrate distance (SSD) was changed from $7 \mathrm{~cm}$ to $16 \mathrm{~cm}$ in steps of $3 \mathrm{~cm}$. After deposition, the films were removed immediately from the hot plate to a wooden surface. Through this arrangement it was possible to have consistency in the results as well as large area deposition. The samples were named as AZO7, AZO10, AZO13 and AZO16 for source substrate distances of 7,10,13 and $16 \mathrm{~cm}$, respectively.

The structural, morphological, electrical, and optical properties of the samples were carried out in detail to analyze the quality of films. Structural properties of the samples were examined by X-ray diffractometer (Bruker D8 Advance) using $\mathrm{CuK}_{\alpha}$ radiation $(\lambda=0.15406 \mathrm{~nm})$. Surface morphology was measured using atomic force microscopy (AFM, XE-100, Park Systems) operating in air whereas scanning electron microscopy (JEOL JSM-6390) is used to probe the topography. Hall effect measurements were done using Ecopia HMS-5000, to measure the 
conductivity of the samples. Photo luminescence was recorded using Horiba Scientific FluoroMax-4 spectrofluorometer. UV-Vis-NIR spectroscopy (SCHIMADZU) was used to evaluate the transmittance properties.

\section{Results and Discussion}

\subsection{Structural Analysis}

X-Ray diffraction measurements were carried out to analyze the main crystalline phases of the prepared thin films. The diffraction patterns were recorded from $20^{\circ}-80^{\circ}$ for all the samples prepared at various source-substrate distances and are shown in Figure 1. XRD pattern of the samples indicates single phase of $\mathrm{ZnO}$ with hexagonal wurtzite structure having peaks in agreement with JCPDS file number 089-0510. All samples show preferential growth along (002) plane, except AZO7. The intensity of (002) peak is observed to be maximum at a source substrate distance of $10 \mathrm{~cm}$. It is observed that, for the sample prepared at the source substrate distance of $7 \mathrm{~cm}$, the growth along (002) plane is too feeble to be noticed. The increased intensity of (002) peak shows the improved crystallinity of the samples along c-axis. 


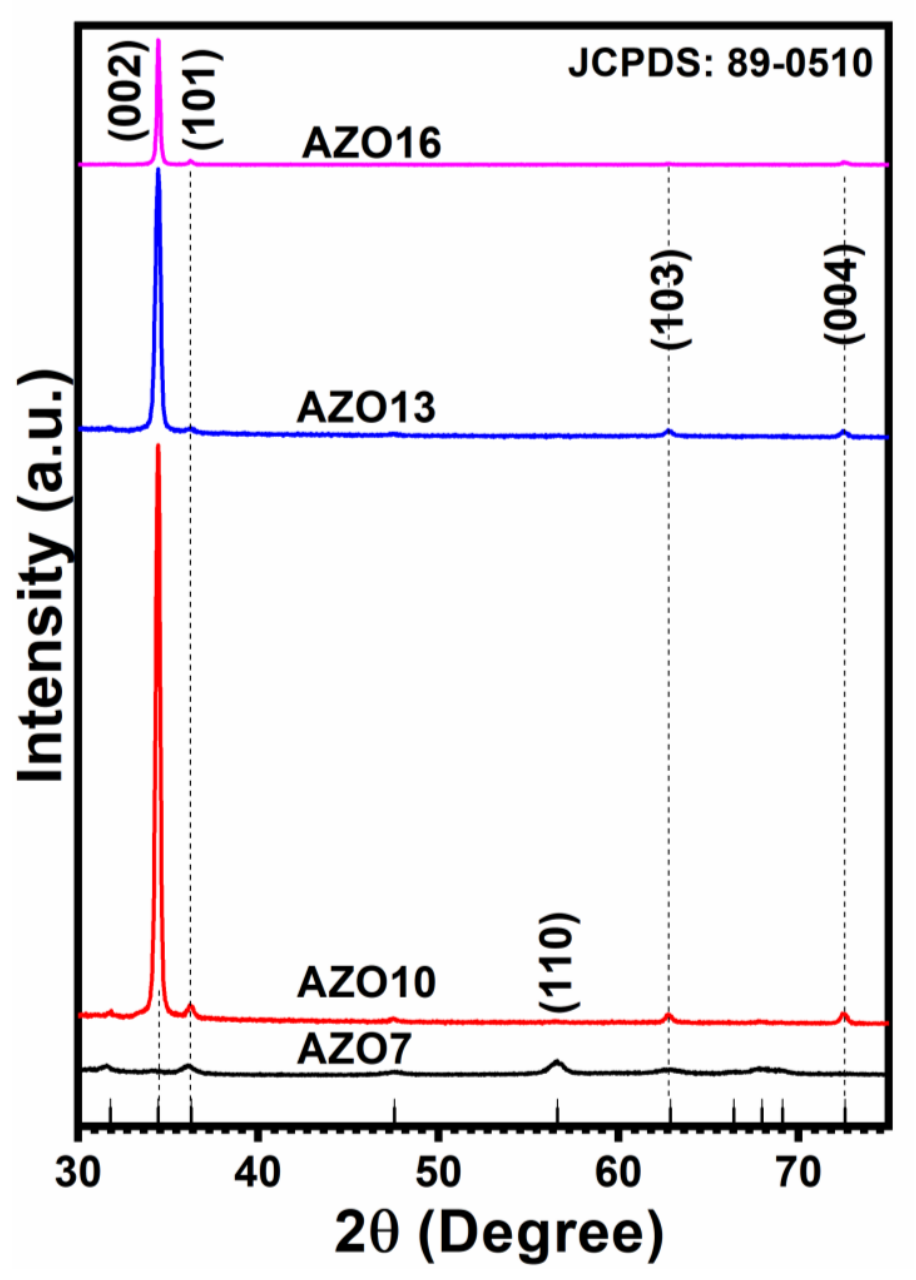

Figure 1. X-ray diffraction patterns of AZO thin films deposited at different source-substrate distances (SSD).

Mean crystallite size was calculated for the samples using Scherrer formula (1)[23].

$$
D=\frac{0.9 \lambda}{\beta \operatorname{Cos} \theta}
$$

Where $\lambda$ is the wavelength of X-ray $\left(\mathrm{Cu} \mathrm{k}_{a}=1.5406 \AA\right), \beta$ is the full width at half maximum and $\theta$ is the Bragg's angle. Grain size shows a variation from $22.74 \mathrm{~nm}$ to $48.64 \mathrm{~nm}$ when the sourcesubstrate distance changes. At a shorter SSD of $7 \mathrm{~cm}$, amount of solution reaching the substrate is larger and the heat absorbed by the solvent molecules in the droplet is not enough to vaporize them completely. Since the droplet has some residual solvent, it spreads over the substrate, as a thin layer which reduces the substrate temperature drastically, leading to a reaction resulting in the formation of film of lesser quality. As the SSD increases, the amount of solution reaching the substrate decreases and effective evaporation of solvent results in homogeneous decomposition 
of solute to form good quality films. At a larger SSD of $16 \mathrm{~cm}$ smaller droplets may be formed which will produce powdery particles and clusters on the substrate resulting in the degradation of film crystallinity. The lattice constants ' $a$ ' and 'c', the average uniform strain $\varepsilon_{\mathrm{zz}}$, the stress developed in the sample film were calculated. The lattice parameters of the hexagonal structured $\mathrm{ZnO}$ were calculated using relation(2) [24].

$$
\frac{1}{d_{h k l}^{2}}=\frac{4}{3}\left(\frac{h^{2}+h k+k^{2}}{a^{2}}\right)+\frac{l^{2}}{c^{2}}
$$

Where, $\mathrm{d}_{\mathrm{hkl}}$, (hkl), 'a' and 'c' represents the inter planar distance, Miller indices and lattice parameters, respectively. The observed 'c' and 'a' value agree with the standard values. The calculated 'c' value for all the samples are found to be less than that for bulk $\mathrm{ZnO}$ and this confirms the presence of residual strain in the films due to the substitution of $\mathrm{Al}^{3+}$ ions with shorter ionic radius $\left(\mathrm{Zn}^{2+}=0.072 \mathrm{~nm}, \mathrm{Al}^{3+}=0.053 \mathrm{~nm}\right)$. The average uniform strain $\varepsilon_{\mathrm{zz}}$, developed in the sample was calculated from the lattice parameters using formula(3)[24].

$$
\varepsilon_{z z}=\frac{c_{f i l m}-c_{b u l k}}{c_{b u l k}}
$$

Where cbulk refers to unstrained lattice parameter for bulk $\mathrm{ZnO}$ with value $5.205 \AA$ and cfilm is the calculated lattice parameter of thin films. Stress in the films $\left(\sigma_{\text {film }}\right)$ were calculated using equation (4)[24].

$$
\sigma_{f i l m}=\frac{2 C_{13}^{2}-C_{33}\left(C_{11}-C_{12}\right)}{C_{13}} \cdot \varepsilon_{z z}
$$

$\mathrm{C}_{11}=208.8, \mathrm{C}_{12}=119.7, \mathrm{C}_{13}=104.2$ and $\mathrm{C}_{33}=213.8 \mathrm{GPa}$, are the elastic stiffness constants of bulk $\mathrm{ZnO}$. The quality of the preferred orientation of a thin film can be quantified by the texture coefficient (TC) which is calculated from the XRD of (hkl) plane using relation (5)[25].

$$
T C_{h k l}=\frac{I(h k l) / I_{0}(h k l)}{1 / N \cdot \sum I(h k l) / I_{0}(h k l)}
$$

$\mathrm{I}(\mathrm{hkl})$ is the intensity of (hkl) peak in AZO film, $\mathrm{I}_{0}(\mathrm{hkl})$ is the intensity of (hkl) peak in bulk $\mathrm{ZnO}$ and ' $\mathrm{N}$ ' is the number of diffraction peaks considered. TChkl is calculated for different orientations such as (100), (002) and (101). The value of texture coefficient implies that 
preferred orientation of film growth in the deposited thin films is along [002]. Table 1 gives information on the variation of crystallite size, stress, strain, and $\mathrm{TC}_{002}$ as a function of sourcesubstrate distance. Besides, a graphical illustration of their variations with SSD can be seen in Figure 2.

Table 1. Various structural properties obtained from the X-ray diffraction patterns of thin films at different SSD.

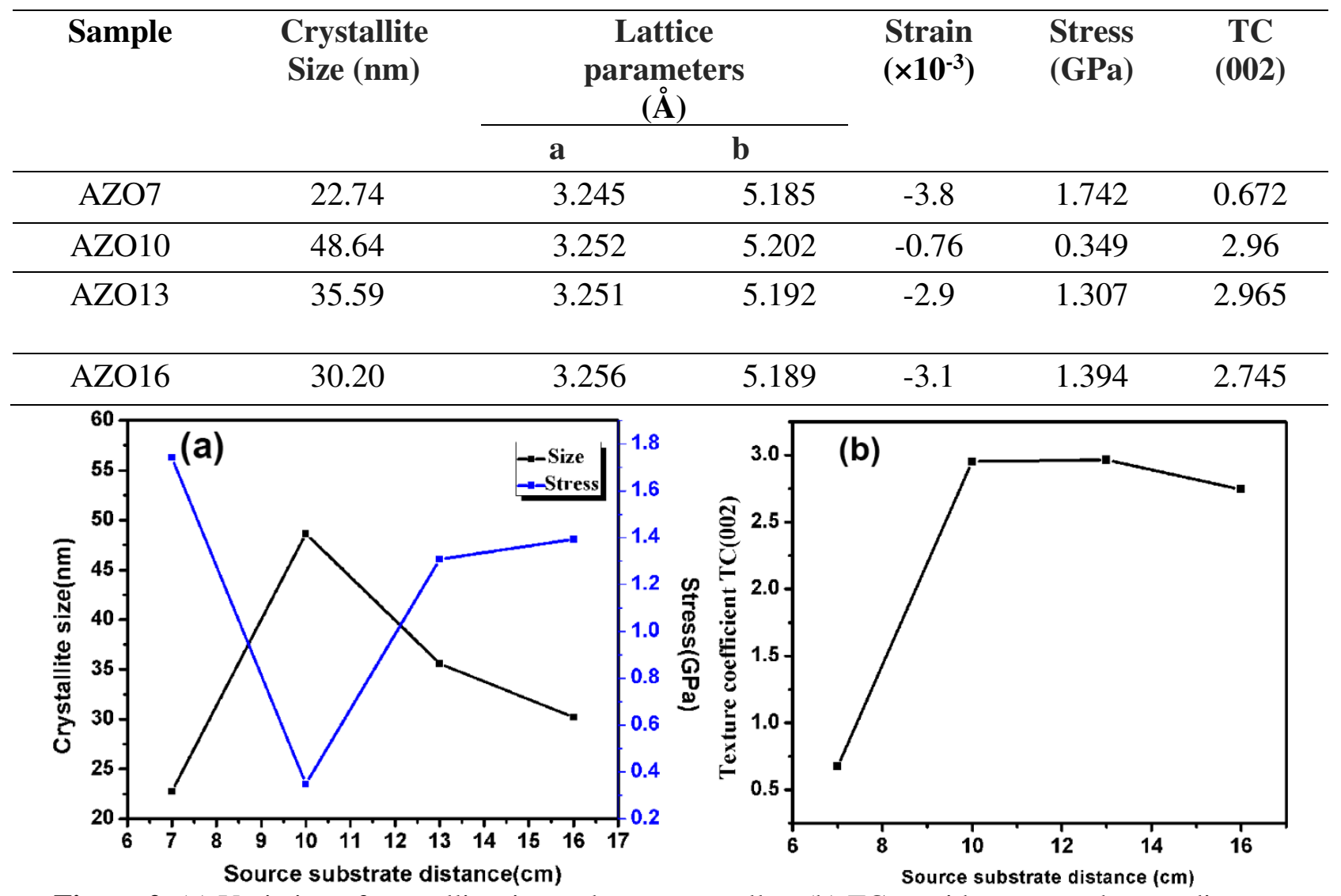

Figure 2. (a) Variation of crystallite size and stress as well as (b) $\mathrm{TC}_{002}$ with source-substrate distance (SSD).

\subsection{Morphological Analysis}

The AFM images of the prepared AZO films are presented in Figure 3(a), Figure 3(b), Figure 3(c) and Figure 3(d). The root mean square (rms) roughness $(\mathrm{Rq})$ parameter, indicating the standard deviation of the surface heights values within a given area, was measured using the WSxM software[26]. Table 2 presents the variation rms values of surface roughness calculated from AFM images. 


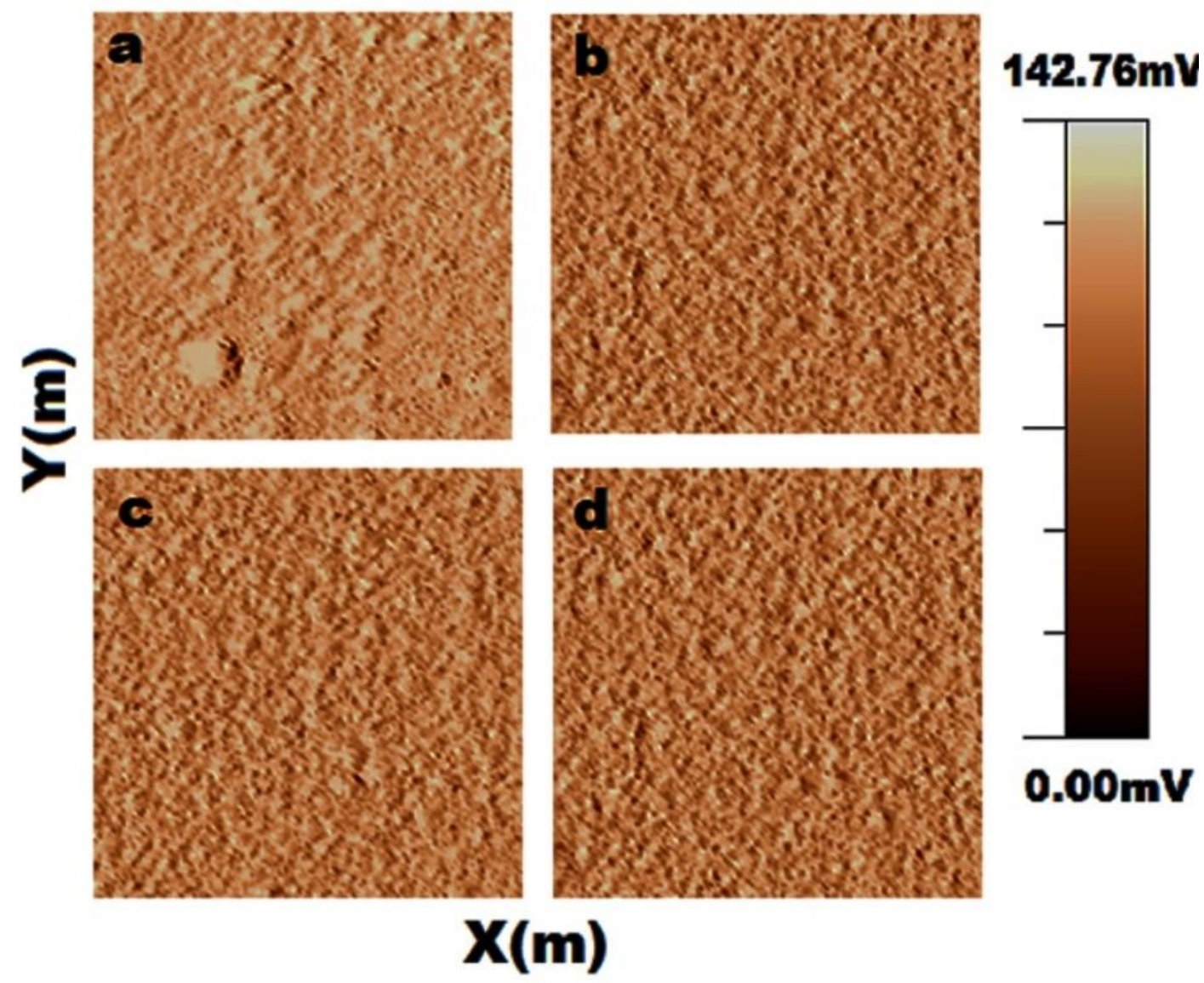

Figure 3. Images from the atomic force microscopy of the (a) AZO7 (b) AZO10 (c) AZO13 and (d) AZO16 samples.

Table 2. The rms roughness values of the different samples as calculated from the AFM images.

\begin{tabular}{cc}
\hline Sample & rms roughness $(\mathbf{n m})$ \\
\hline AZO7 & 39.5 \\
\hline AZO10 & 20.9 \\
\hline AZO13 & 21.3 \\
\hline AZO16 & 22.9 \\
\hline
\end{tabular}




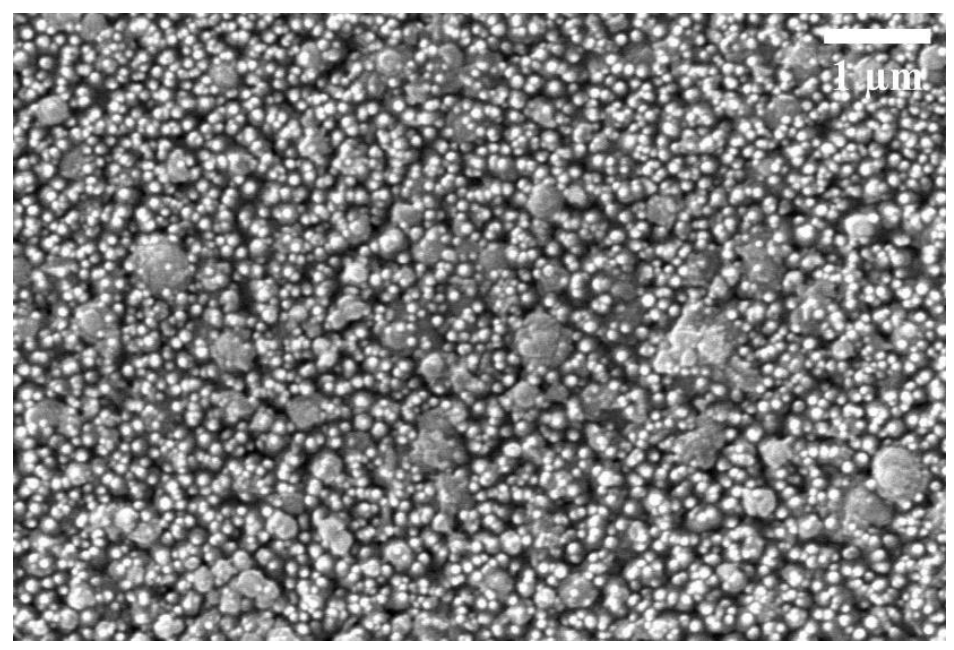

Figure 4. SEM image of the AZO10 thin film deposited at a source-substrate distance of $10 \mathrm{~cm}$.

The scanning electron microscopy was used to identify the uniformly distributed particles on the surface of the thin film deposited at a source substrate distance of $10 \mathrm{~cm}$. The surface has smaller particles in the range of $80-120 \mathrm{~nm}$ as well as bigger agglomerated particles in the range of 300$480 \mathrm{~nm}$.

\subsection{Electrical Studies}

To understand the transport properties and to estimate the conductivity of the thin films we employed Hall effect measurements. Table 3 lists the variation of electrical properties with source-substrate distance. Changes in carrier concentration as well as the mobility lead to conductivity variations in the prepared samples. The increase in carrier concentration may be due to the formation of metal rich oxide films. When the electrical resistivity of AZO films as a function of source-substrate distance (SSD) was analyzed, it was found that resistivity decreases with decrease in SSD from $16 \mathrm{~cm}$, reaches the minimum value of $3.628 \times 10^{-3} \Omega \mathrm{cm}$ for AZO10. This decrease is due to the increase of free carrier concentration as a result of the donor $\mathrm{Al}^{3+}$ ions incorporated as substitutional ions in $\mathrm{Zn}^{2+}$ cation sites or in interstitial positions[27]. However, after reaching the minimum value, the resistivity shows an increase for AZO7. This may be due to the decrease in carrier concentration. All samples reveal the intrinsic n-type characteristic of $\mathrm{ZnO}$ which was further enhanced by the doping of donor $\mathrm{Al}^{3+}$ cations.

Table 3. The electrical properties of various AZO thin films from the Hall effect measurements.

\begin{tabular}{ccccc}
\hline Sample & Carrier concentration $\mathbf{( \mathbf { c m } ^ { - 3 } )}$ & $\begin{array}{c}\text { Resistivity } \\
(\mathbf{\Omega . c m})\end{array}$ & $\begin{array}{c}\text { Conductivity } \\
(\mathbf{S} / \mathbf{c m})\end{array}$ & $\begin{array}{c}\text { Mobility } \\
\left(\mathbf{c m}^{\mathbf{2}} \mathbf{V}^{-\mathbf{1}} \mathbf{~ s}^{\mathbf{- 1}}\right)\end{array}$ \\
\hline AZO7 & $7.189 \times 10^{18}$ & $2.782 \times 10^{-1}$ & 3.5945 & 3.121 \\
\hline
\end{tabular}




\begin{tabular}{ccccc}
\hline AZO10 & $4.065 \times 10^{20}$ & $3.628 \times 10^{-3}$ & 275.63 & 4.233 \\
\hline AZO13 & $1.141 \times 10^{20}$ & $2.955 \times 10^{-2}$ & 33.84 & 1.851 \\
\hline AZO16 & $5.995 \times 10^{19}$ & $2.568 \times 10^{-1}$ & 3.89 & 0.4054 \\
\hline
\end{tabular}

\subsection{Optical Analysis}

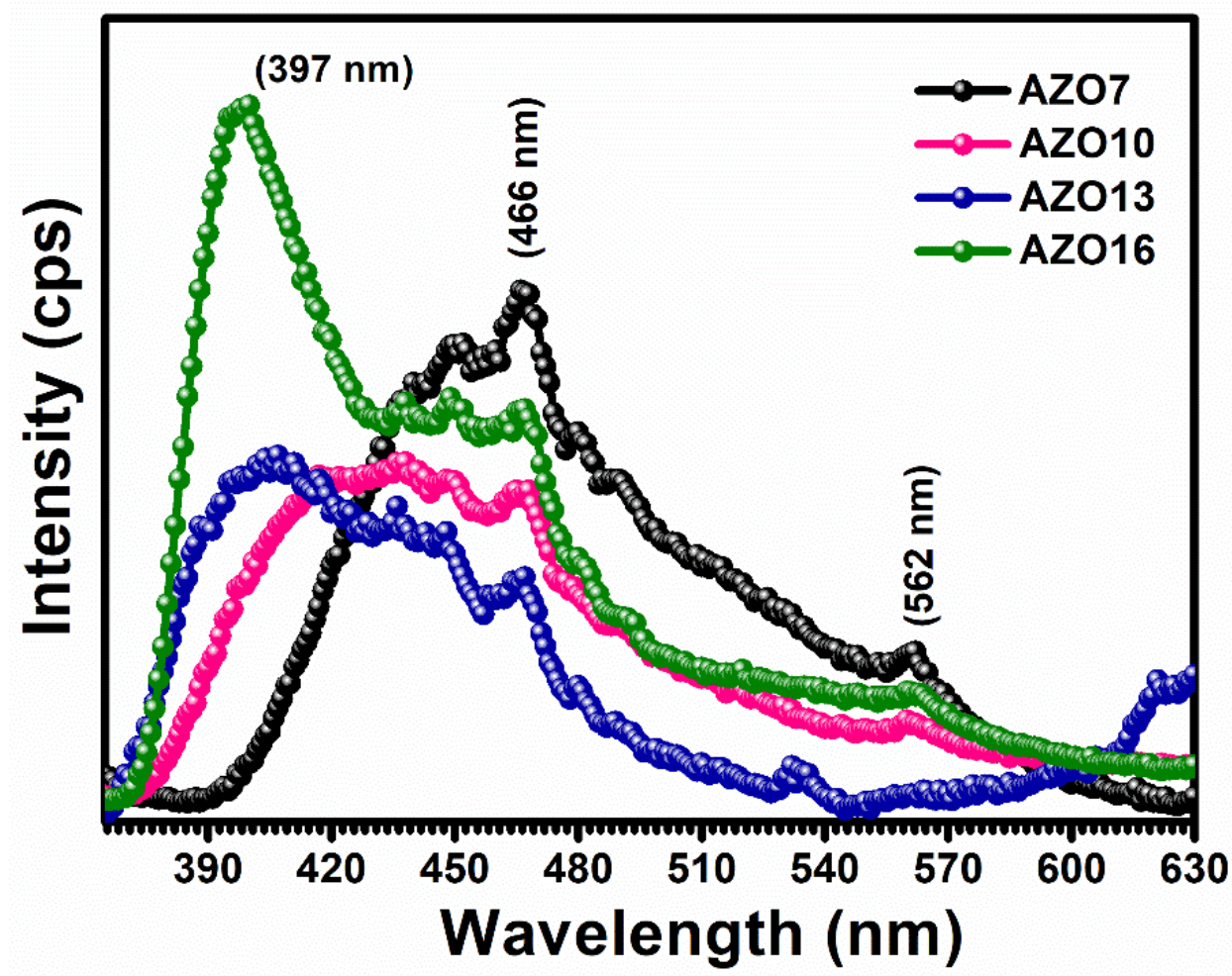

Figure 5. Photoluminescence spectra of AZO samples deposited at different source-substrate distances.

Figure 5 depicts the photoluminescence spectra of the spray deposited AZO samples. Intense emission around $397 \mathrm{~nm}$ exhibited by the sample AZO16 appears with lower intensities in AZO10 and AZO13. However, such emission is not notable in the case of AZO7 sample due to the prominent defect level emissions. The different defect levels in $\mathrm{ZnO}$ and the emissions observed in the PL spectra are compared through an energy level diagram in Figure 6. The energy corresponding to this emission is comparable with the band gaps observed and can be attributed to the near band edge emissions such as zinc interstitials $\left(\mathrm{Zn}_{\mathrm{i}}\right)$ to valance band (VB) transition. Here, the zinc rich conditions might have resulted in more density of $\mathrm{Zn}_{\mathrm{i}}$ in the samples [28]. Furthermore, emissions around 436 nm, 449 nm, 466 nm, 480 and 562 nm were observed in the case of all the spray deposited AZO thin films. The weak blue PL emission at about $436 \mathrm{~nm}$ is attributed to the recombination of carriers trapped at $\mathrm{Zn}_{\mathrm{i}}$ (electrons) and zinc vacancies $\left(\mathrm{V}_{\mathrm{Zn}}\right)$ (holes)[29]. The emission peak around $449 \mathrm{~nm}$ and $466 \mathrm{~nm}$ are caused by 
various extended $\mathrm{Zn}_{\mathrm{i}}$ levels[30] as illustrated in Figure 6. The peak at $562 \mathrm{~nm}$ correspond to transitions to doubly charged oxygen vacancies $\left(\mathrm{V}_{0}{ }^{+2}\right)$ in the grain-boundary-induced depletion regions[31]. In addition, a feeble emission around $480 \mathrm{~nm}$ is associated to the energy level of neutral oxygen vacancy $V_{0}(2.57 \mathrm{eV}$ above the valence band)[32][33].

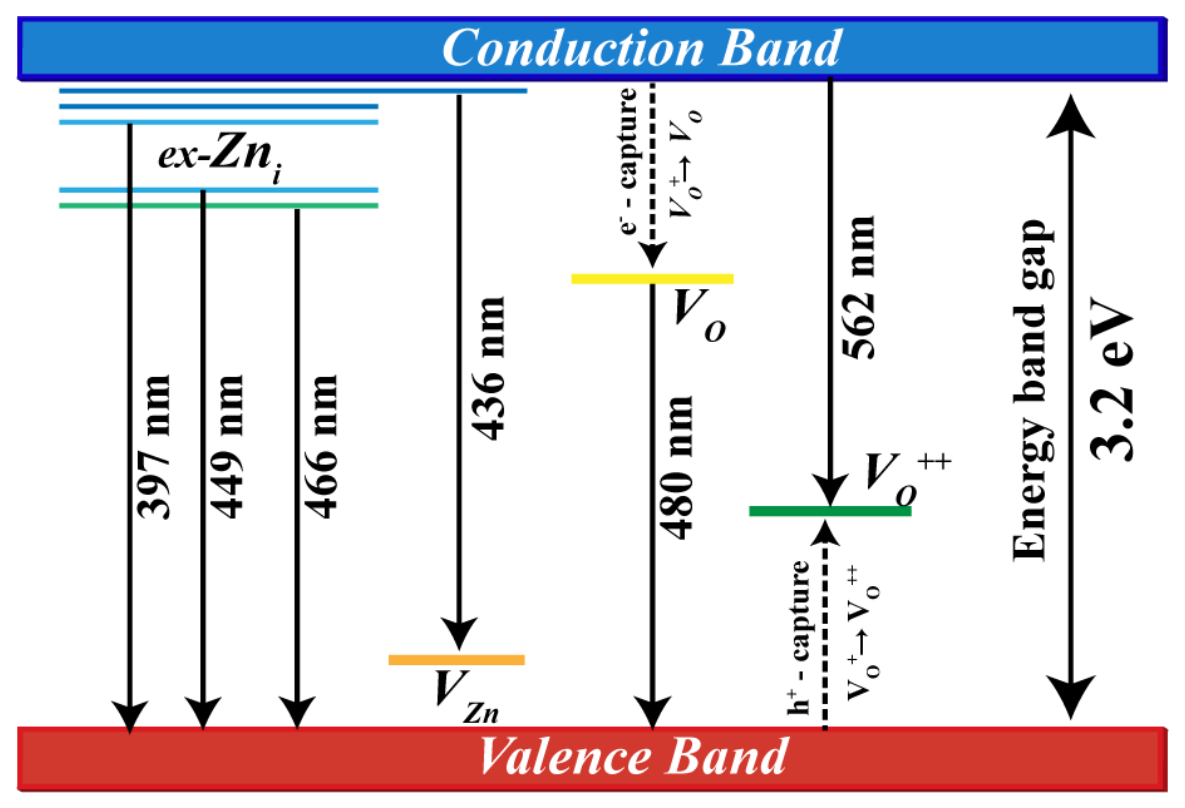

Figure 6. Energy band diagram of AZO samples illustrating the possible defect levels.

Figure 7(a) and Figure 7(b) shows the transmission and absorbance spectra of AZO thin films in the range of 350-1000 $\mathrm{nm}$. An average transmission of $85 \%$ was shown by the sample AZO10 in the visible region. The $(h v)$ Vs $(\alpha h v)^{2}$ plot as per the tauc relation (6) was used to determine the band gap $\left(\mathrm{Eg}_{\mathrm{g}}\right)$ of the thin films and is presented in the Figure 7(c).

$$
\alpha h \vartheta=B\left(h \vartheta-E_{g}\right)^{n}
$$

Where $\mathrm{B}$ is the band tailing factor, $\mathrm{h}$ is the planks constant, $v$ is the frequency, $\mathrm{n}$ is $1 / 2$ for direct allowed transition and $\alpha$ is the absorption coefficient which can be calculated by,

$$
\alpha=\frac{1}{t} \times \ln \left(\frac{1}{T}\right)
$$

Where, $\mathrm{t}$ is the thickness and $\mathrm{T}$ is transmission of the deposited AZO thin films.

At the smallest SSD in the study $(7 \mathrm{~cm})$, the observed band gap is $3.22 \mathrm{eV}$. The lowest band gap of $3.17 \mathrm{eV}$ was calculated for AZO10 which was deposited at a source-substrate distance of 10 $\mathrm{cm}$. At further distances of $13 \mathrm{~cm}$ and $16 \mathrm{~cm}$, the band gap was observed to be increasing to 3.25 $\mathrm{eV}$ and $3.27 \mathrm{eV}$, respectively. The small band gap of the AZO10 is due to the better charge carrier transport properties as a consequence of excellent crystallinity. 

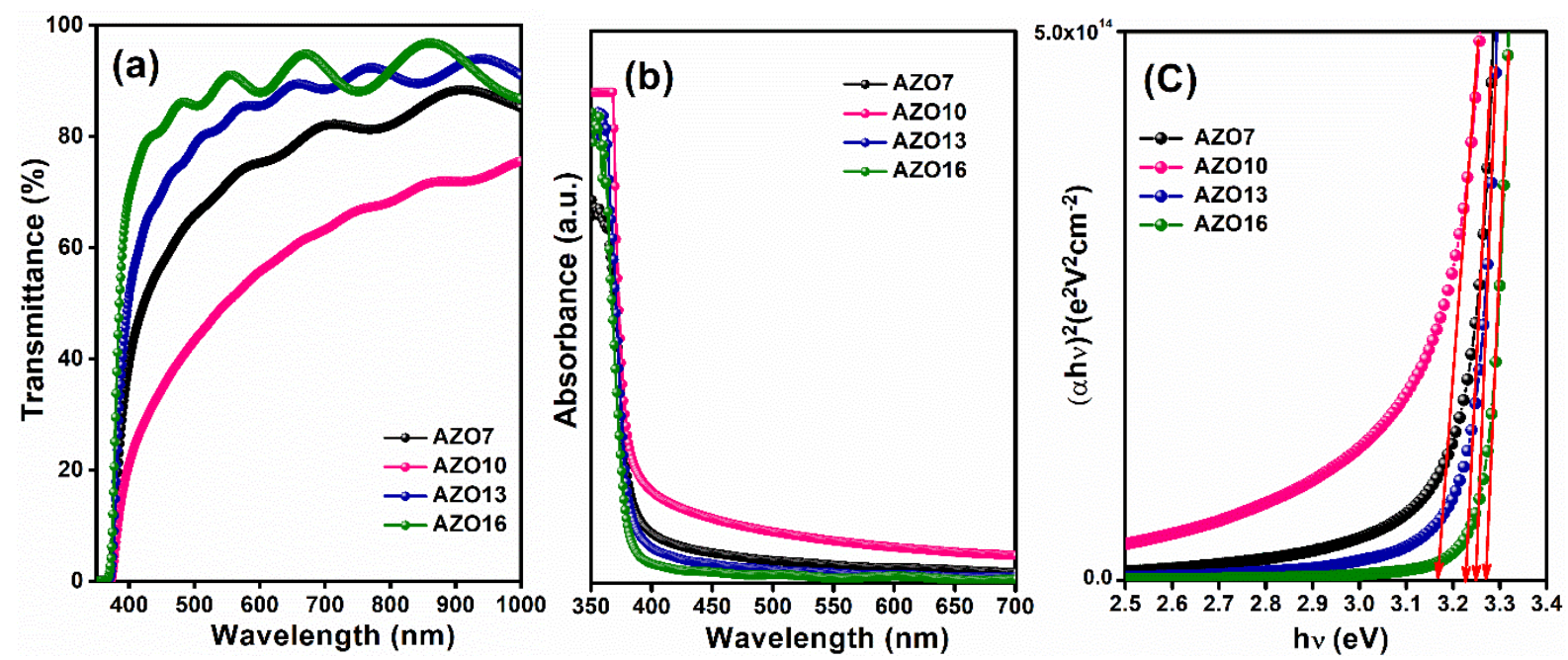

Figure 7. (a)Transmission spectra (b) absorbance spectra and (c) tauc plots revealing optical band gaps of the AZO samples.

\section{Conclusions}

In conclusion, the source-substrate distance (SSD) have been identified as an important parameter during the spray deposition of aluminium doped $\mathrm{ZnO}$ thin films, an established transparent electrode in optoelectronic devices. Our studies suggests that SSD has significant effects on the quality of the spray deposited thin films affecting their structural, morphological, electrical, and optical properties. While all other deposition parameters were kept unchanged, a highly crystalline sample with improved conductivity and transmittance was obtained for a source-substrate distance of $10 \mathrm{~cm}$ (AZO10). The resistivity of this sample was measured to be $3.628 \times 10^{-3} \Omega \mathrm{cm}$ with appreciable transmission in the visible region. Through these investigations the authors strongly encourage the optimization of source-substrate distance while fabricating thin films by the chemical spray pyrolysis method which is technologically important as a truly scalable technique for optoelectronic device fabrication.

\section{Acknowledgement}

The research works in this report were conducted using the economic support from the Department of Atomic Energy-Board of Research in Nuclear Sciences (DAE-BRNS), India (No. 34/14/58/2014-BRNS).

\section{References}

[1] F. Rahman, Zinc oxide light-emitting diodes: a review, Opt. Eng. 58 (2019) 1. doi:10.1117/1.oe.58.1.010901. 
[2] R. Khokhra, B. Bharti, H.-N. Lee, R. Kumar, Visible and UV photo-detection in $\mathrm{ZnO}$ nanostructured thin films via simple tuning of solution method, Sci. Rep. 7 (2017) 15032. doi:10.1038/s41598-017-15125-x.

[3] S. Chu, G. Wang, W. Zhou, Y. Lin, L. Chernyak, J. Zhao, J. Kong, L. Li, J. Ren, J. Liu, Electrically pumped waveguide lasing from $\mathrm{ZnO}$ nanowires, Nat. Nanotechnol. 6 (2011) 506-510. doi:10.1038/nnano.2011.97.

[4] A. Janotti, C.G. Van De Walle, Fundamentals of zinc oxide as a semiconductor, Reports Prog. Phys. 72 (2009) 126501. doi:10.1088/0034-4885/72/12/126501.

[5] B.N. Pawar, D.H. Ham, R.S. Mane, T. Ganesh, B.W. Cho, S.H. Han, Fluorine-doped zinc oxide transparent and conducting electrode by chemical spray synthesis, Appl. Surf. Sci. 254 (2008) 6294-6297. doi:10.1016/j.apsusc.2008.02.088.

[6] K. Mahmood, B.S. Swain, H.S. Jung, Controlling the surface nanostructure of $\mathrm{ZnO}$ and Al-doped $\mathrm{ZnO}$ thin films using electrostatic spraying for their application in $12 \%$ efficient perovskite solar cells, Nanoscale. 6 (2014) 9127-9138. doi:10.1039/c4nr02065k.

[7] M. Ajili, M. Castagné, N.K. Turki, Study on the doping effect of Sn-doped ZnO thin films, Superlattices Microstruct. 53 (2013) 213-222. doi:10.1016/j.spmi.2012.10.012.

[8] H. Kim, C.M. Gilmore, J.S. Horwitz, A. Piqué, H. Murata, G.P. Kushto, R. Schlaf, Z.H. Kafafi, D.B. Chrisey, Transparent conducting aluminum-doped zinc oxide thin films for organic light-emitting devices, Appl. Phys. Lett. 76 (2000) 259-261.

doi:10.1063/1.125740.

[9] P. Ray, V. Ramgopal Rao, Al-doped $\mathrm{ZnO}$ thin-film transistor embedded micro-cantilever as a piezoresistive sensor, Appl. Phys. Lett. 102 (2013) 064101. doi:10.1063/1.4792062.

[10] M. Spalla, E. Planes, L. Perrin, M. Matheron, S. Berson, L. Flandin, Alternative Electron Transport Layer Based on Al-Doped $\mathrm{ZnO}$ and $\mathrm{SnO} 2$ for Perovskite Solar Cells: Impact on Microstructure and Stability, ACS Appl. Energy Mater. 2 (2019) 7183-7195. doi:10.1021/acsaem.9b01160.

[11] C. Bhoomanee, P. Ruankhama, S. Choopun, A. Prathan, D. Wongratanaphisan, Effect of Al-doped $\mathrm{ZnO}$ for Electron Transporting Layer in Planar Perovskite solar cells, Mater. Today Proc. 17 (2019) 1259-1267. doi:10.1016/j.matpr.2019.06.014.

[12] W. Gao, Z. Li, ZnO thin films produced by magnetron sputtering, in: Ceram. Int., Elsevier, 2004: pp. 1155-1159. doi:10.1016/j.ceramint.2003.12.197.

[13] J.G. Lu, T. Kawaharamura, H. Nishinaka, Y. Kamada, T. Ohshima, S. Fujita, Zno-based thin films synthesized by atmospheric pressure mist chemical vapor deposition, J. Cryst. Growth. 299 (2007) 1-10. doi:10.1016/j.jcrysgro.2006.10.251.

[14] Y.W. Heo, K. Ip, S.J. Pearton, D.P. Norton, J.D. Budai, Growth of $\mathrm{ZnO}$ thin films on cplane $\mathrm{Al} 2 \mathrm{O} 3$ by molecular beam epitaxy using ozone as an oxygen source, Appl. Surf. 
Sci. 252 (2006) 7442-7448. doi:10.1016/j.apsusc.2005.08.094.

[15] V. Craciun, J. Elders, J.G.E. Gardeniers, I.W. Boyd, Characteristics of high quality ZnO thin films deposited by pulsed laser deposition, Appl. Phys. Lett. 65 (1994) 2963-2965. doi:10.1063/1.112478.

[16] S. Ilican, Y. Çağlar, M.B. Caglar, Preparation and characterization of $\mathrm{ZnO}$ thin films deposited by sol-gel spin coating method, (2008).

[17] T. Mahalingam, V.S. John, M. Raja, Y.K. Su, P.J. Sebastian, Electrodeposition and characterization of transparent $\mathrm{ZnO}$ thin films, Sol. Energy Mater. Sol. Cells. 88 (2005) 227-235. doi:10.1016/j.solmat.2004.06.021.

[18] C.M. Muiva, T.S. Sathiaraj, K. Maabong, Effect of doping concentration on the properties of aluminium doped zinc oxide thin films prepared by spray pyrolysis for transparent electrode applications, Ceram. Int. 37 (2011) 555-560.

doi:10.1016/j.ceramint.2010.09.042.

[19] H. Chen, X. Ding, X. Pan, T. Hayat, A. Alsaedi, Y. Ding, S. Dai, Comprehensive studies of air-brush spray deposition used in fabricating high-efficiency $\mathrm{CH} 3 \mathrm{NH} 3 \mathrm{PbI} 3$ perovskite solar cells: Combining theories with practices, J. Power Sources. 402 (2018) 82-90. doi:10.1016/j.jpowsour.2018.07.097.

[20] R.S. Miller, K. Harstad, J. Bellan, Evaluation of equilibrium and non-equilibrium evaporation models for many-droplet gas-liquid flow simulations, Int. J. Multiph. Flow. 24 (1998) 1025-1055. doi:10.1016/S0301-9322(98)00028-7.

[21] D.H. Charlesworth, W.R. Marshall, Evaporation from drops containing dissolved solids, AIChE J. 6 (1960) 9-23. doi:10.1002/aic.690060104.

[22] D. Perednis, L.J. Gauckler, Thin film deposition using spray pyrolysis, J. Electroceramics. 14 (2005) 103-111. doi:10.1007/s10832-005-0870-x.

[23] A. Gahtar, A. Rahal, B. Benhaoua, S. Benramache, A comparative study on structural and optical properties of $\mathrm{ZnO}$ and $\mathrm{Al}$-doped $\mathrm{ZnO}$ thin films obtained by ultrasonic spray method using different solvents, Optik (Stuttg). 125 (2014) 3674-3678. doi:10.1016/j.ijleo.2014.01.078.

[24] R. Amiruddin, S. Devasia, D.K. Mohammedali, M.C.S. Kumar, Investigation on P-N dual acceptor doped p-type $\mathrm{ZnO}$ thin films and subsequent growth of pencil-like nanowires, Semicond. Sci. Technol. 30 (2015) 035009. doi:10.1088/0268-1242/30/3/035009.

[25] L. Znaidi, T. Touam, D. Vrel, N. Souded, S. Yahia, O. Brinza, A. Fischer, A. Boudrioua, AZO Thin Films by Sol-Gel Process for Integrated Optics, Coatings. 3 (2013) 126-139. doi:10.3390/coatings3030126.

[26] I. Horcas, R. Fernández, J.M. Gómez-Rodríguez, J. Colchero, J. Gómez-Herrero, A.M. Baro, WSXM: A software for scanning probe microscopy and a tool for nanotechnology, 
Rev. Sci. Instrum. 78 (2007) 013705. doi:10.1063/1.2432410.

[27] A. El Manouni, F.J. Manjón, M. Mollar, B. Marí, R. Gómez, M.C. López, J.R. RamosBarrado, Effect of aluminium doping on zinc oxide thin films grown by spray pyrolysis, Superlattices Microstruct. 39 (2006) 185-192. doi:10.1016/j.spmi.2005.08.041.

[28] C.H. Ahn, Y.Y. Kim, D.C. Kim, S.K. Mohanta, H.K. Cho, A comparative analysis of deep level emission in $\mathrm{ZnO}$ layers deposited by various methods, J. Appl. Phys. 105 (2009) 013502. doi:10.1063/1.3054175.

[29] K.H. Tam, C.K. Cheung, Y.H. Leung, A.B. Djurišić, C.C. Ling, C.D. Beling, S. Fung, W.M. Kwok, W.K. Chan, D.L. Phillips, L. Ding, W.K. Ge, Defects in ZnO nanorods prepared by a hydrothermal method, J. Phys. Chem. B. 110 (2006) 20865-20871. doi:10.1021/jp063239w.

[30] H. Zeng, G. Duan, Y. Li, S. Yang, X. Xu, W. Cai, Blue luminescence of ZnO nanoparticles based on non-equilibrium processes: Defect origins and emission controls, Adv. Funct. Mater. 20 (2010) 561-572. doi:10.1002/adfm.200901884.

[31] J.D. Ye, S.L. Gu, F. Qin, S.M. Zhu, S.M. Liu, X. Zhou, W. Liu, L.Q. Hu, R. Zhang, Y. Shi, Y.D. Zheng, Correlation between green luminescence and morphology evolution of ZnO films, Appl. Phys. A Mater. Sci. Process. 81 (2005) 759-762. doi:10.1007/s00339004-2996-0.

[32] S. Chakrabarti, D. Ganguli, S. Chaudhuri, Photoluminescence of $\mathrm{ZnO}$ nanocrystallites confined in sol gel silica matrix, J. Phys. D. Appl. Phys. 36 (2003) 146-151. doi: $10.1088 / 0022-3727 / 36 / 2 / 311$.

[33] S. Vempati, J. Mitra, P. Dawson, One-step synthesis of $\mathrm{ZnO}$ nanosheets: A blue-white fluorophore, Nanoscale Res. Lett. 7 (2012) 470. doi:10.1186/1556-276X-7-470. 
Figures

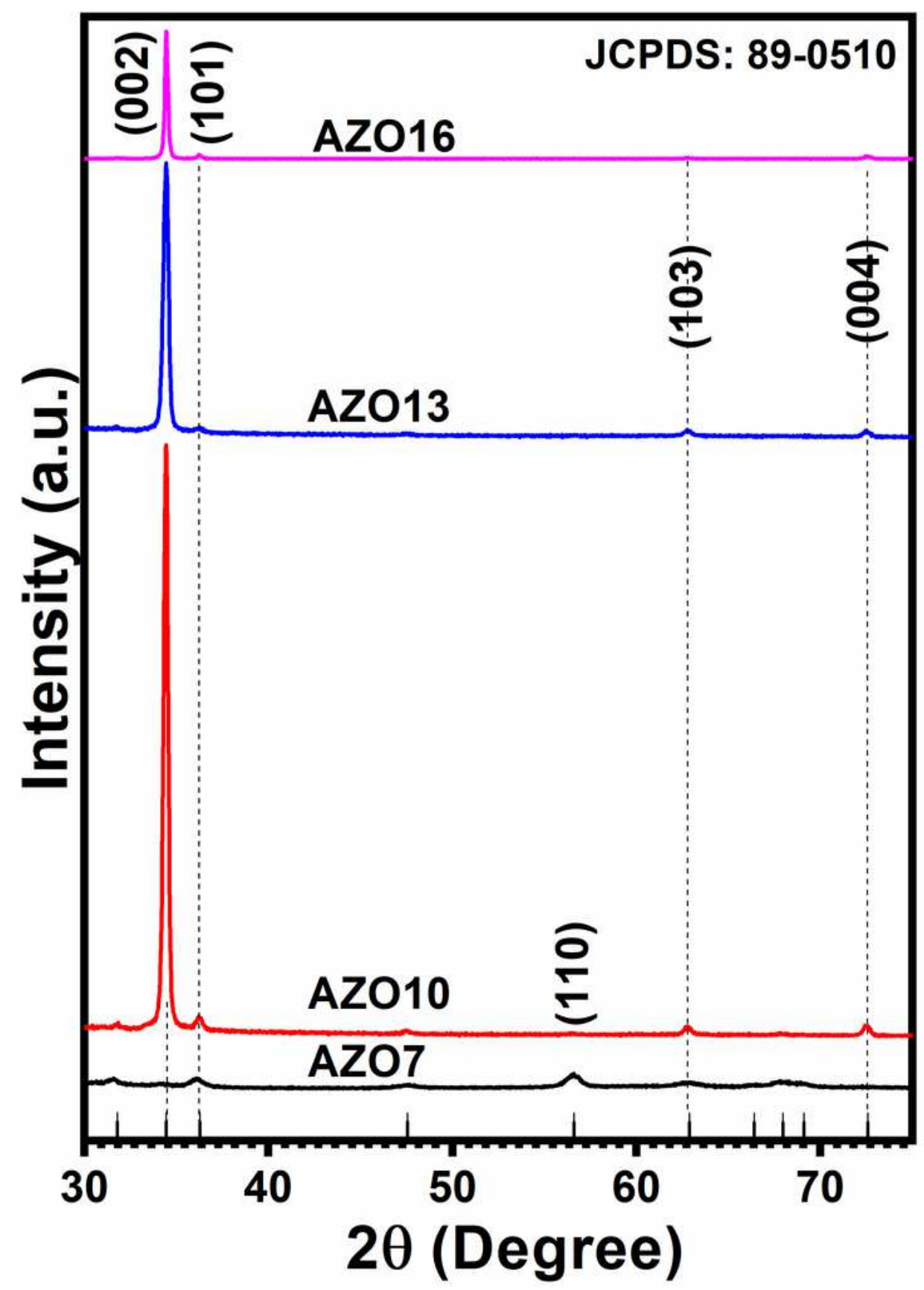

Figure 1

X-ray diffraction patterns of AZO thin films deposited at different source-substrate distances (SSD). 

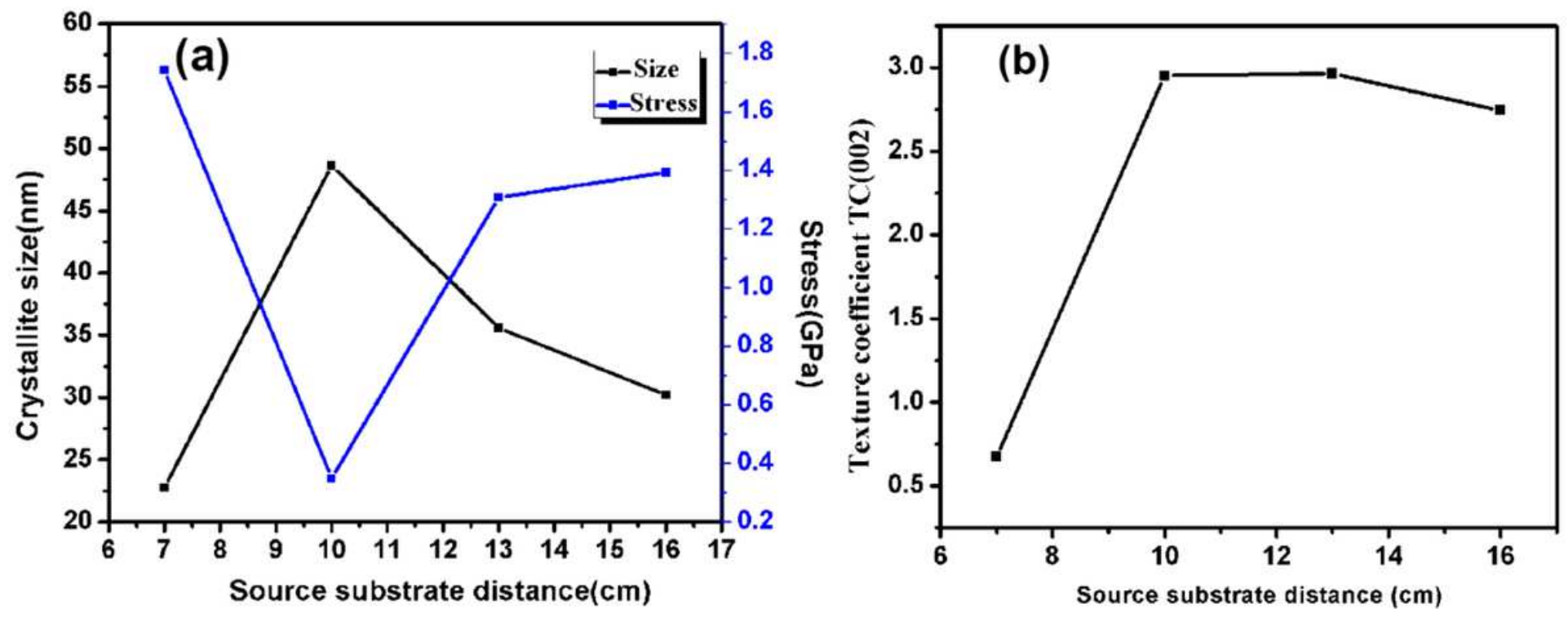

Figure 2

(a) Variation of crystallite size and stress as well as (b) TC002 with source-substrate distance (SSD). 

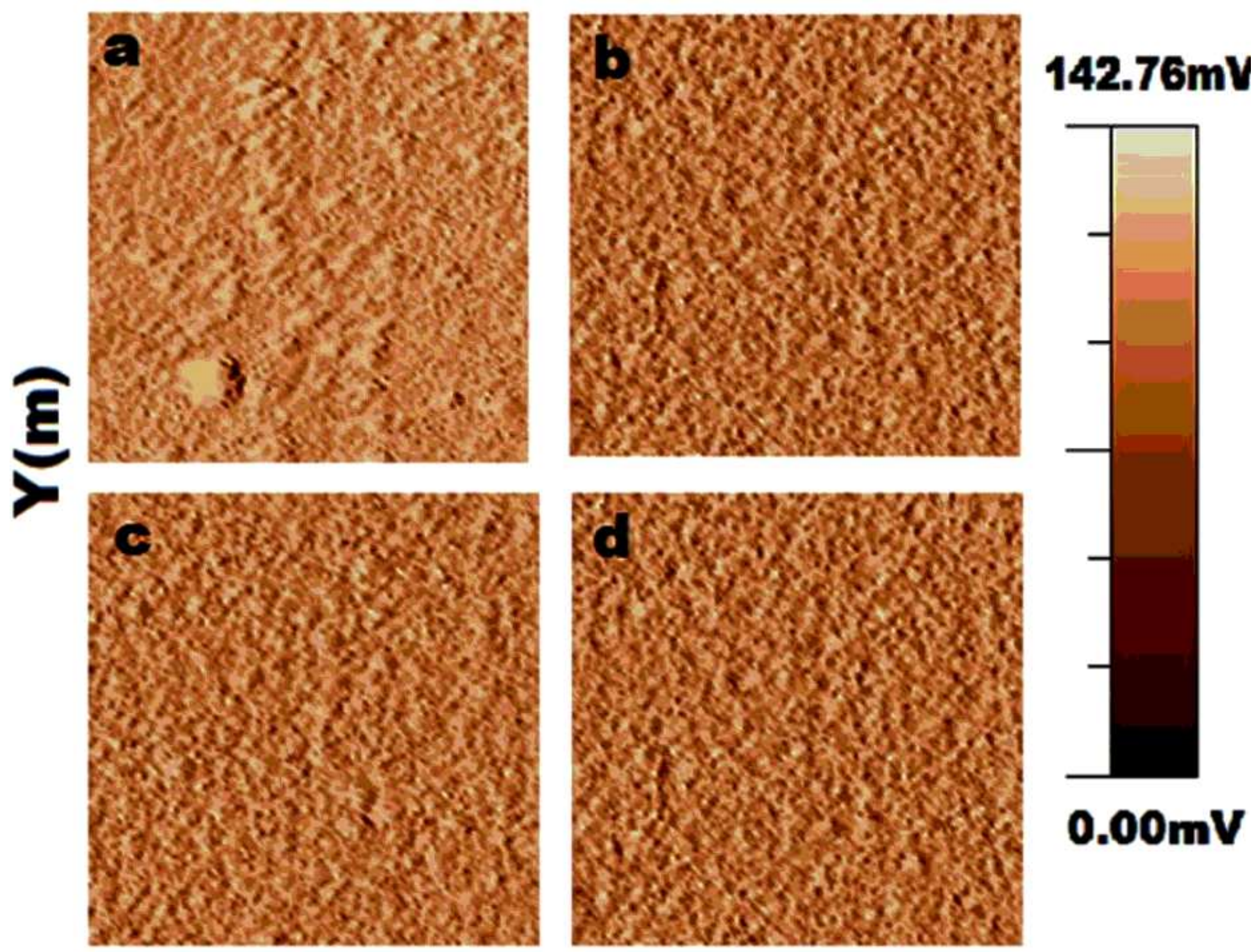

\section{$\mathbf{X}(\mathbf{m})$}

Figure 3

Images from the atomic force microscopy of the (a) AZO7 (b) AZ010 (c) AZ013 and (d) AZ016 samples. 


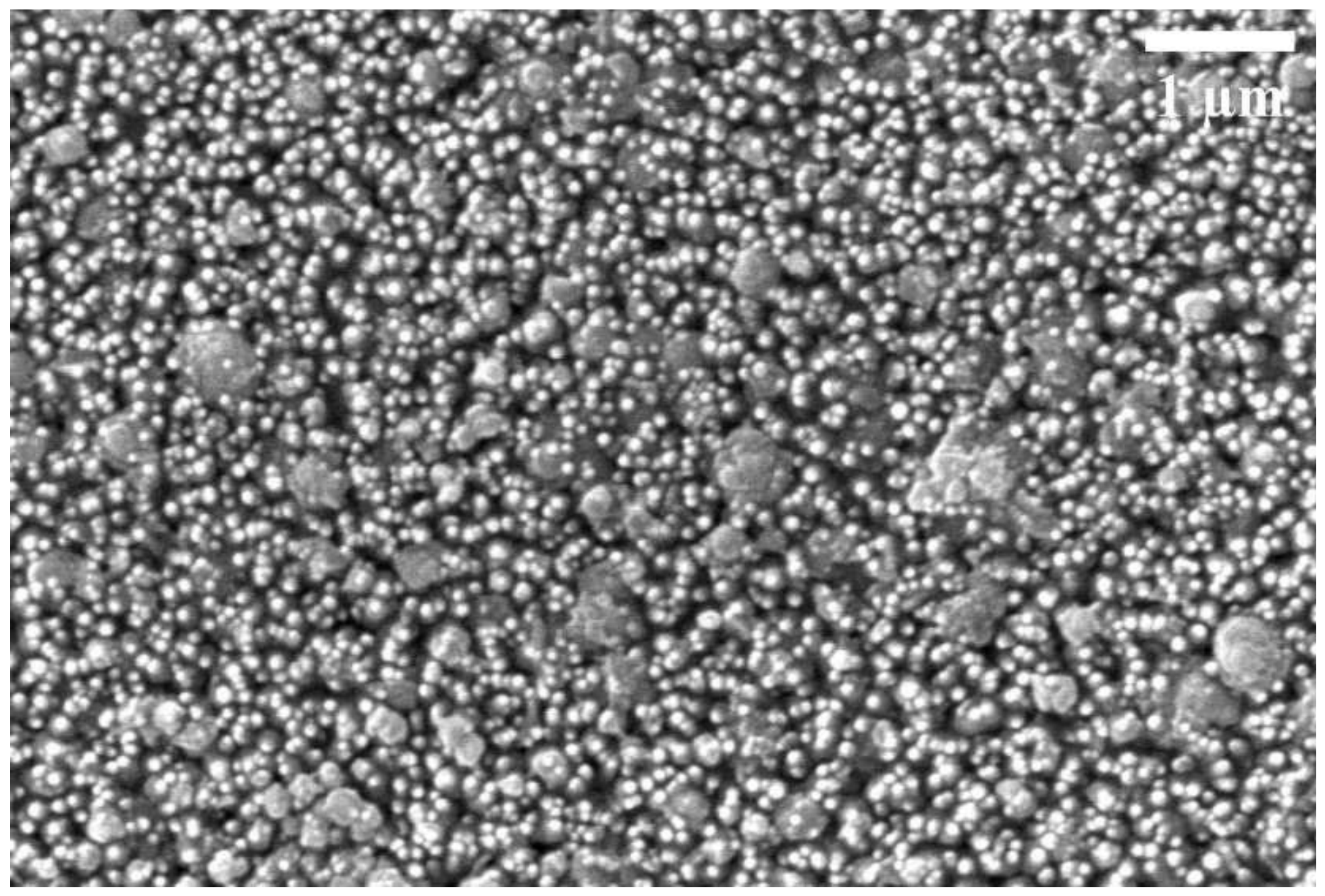

Figure 4

SEM image of the AZ010 thin film deposited at a source-substrate distance of $10 \mathrm{~cm}$. The scanning electron microscopy was used to identify the uniformly distributed particles on the surface of the thin film deposited at a source substrate distance of $10 \mathrm{~cm}$. The surface has smaller particles in the range of 80 $120 \mathrm{~nm}$ as well as bigger agglomerated particles in the range of $300-480 \mathrm{~nm}$. 


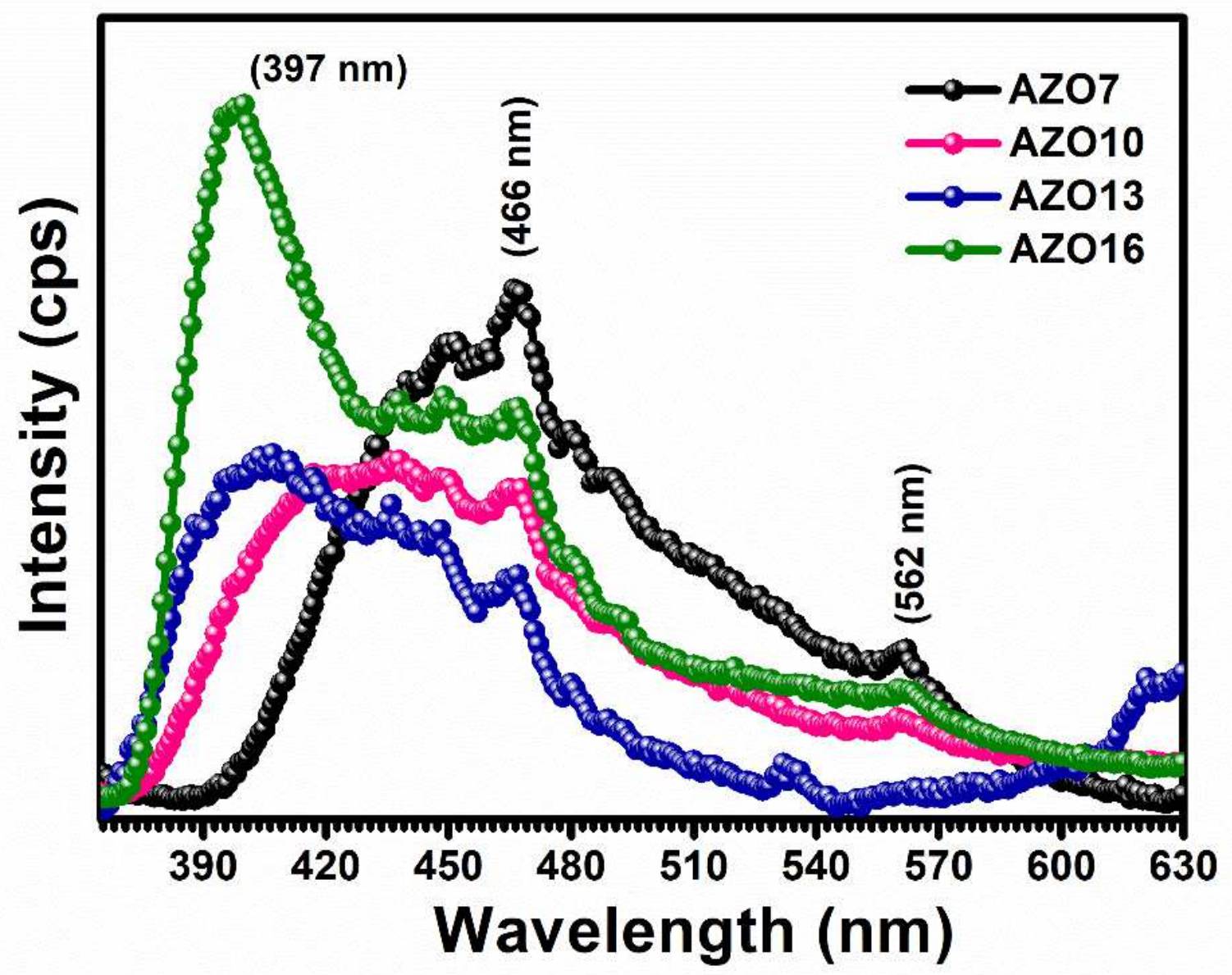

Figure 5

Photoluminescence spectra of AZO samples deposited at different source-substrate distances. 


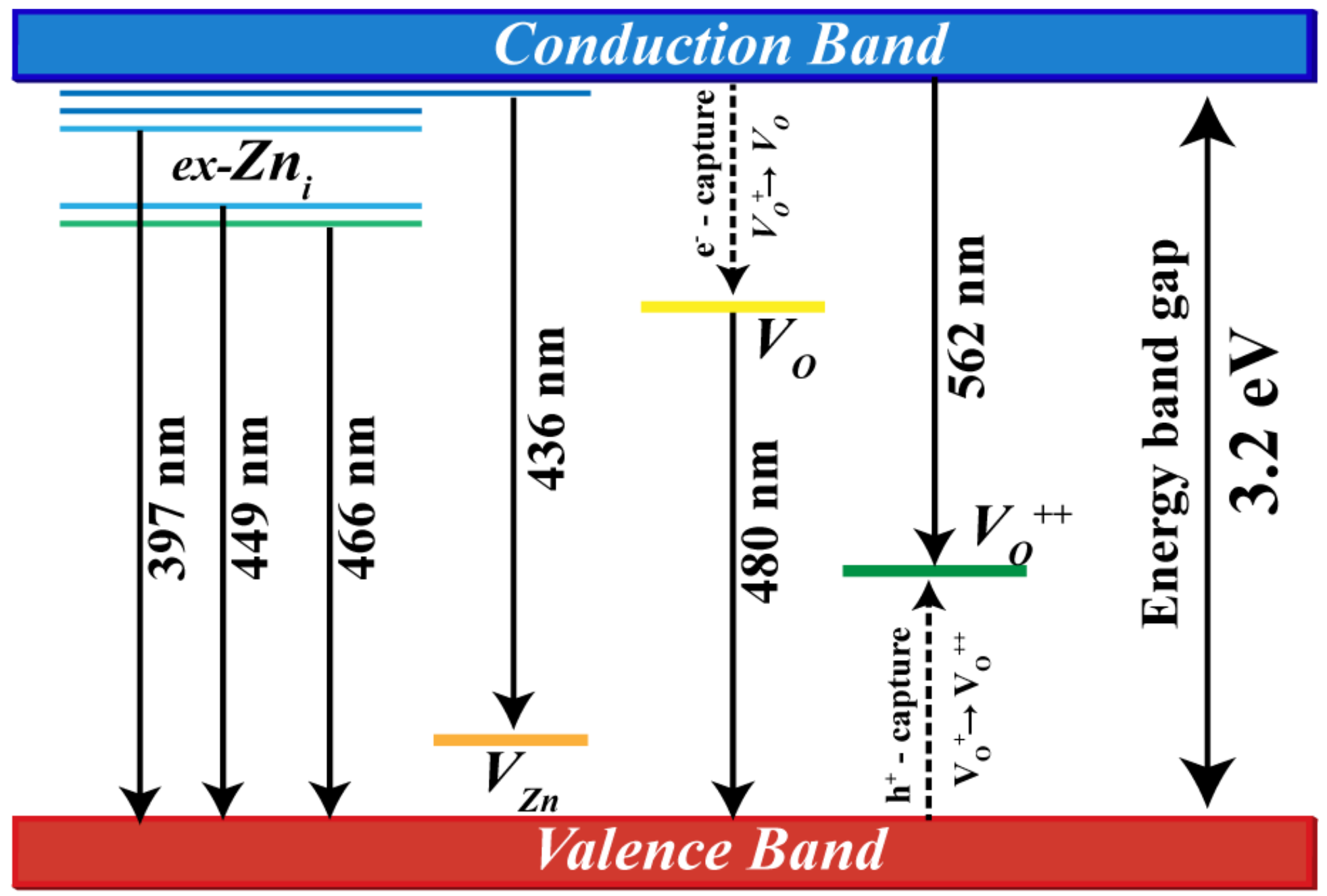

Figure 6

Energy band diagram of AZO samples illustrating the possible defect levels.
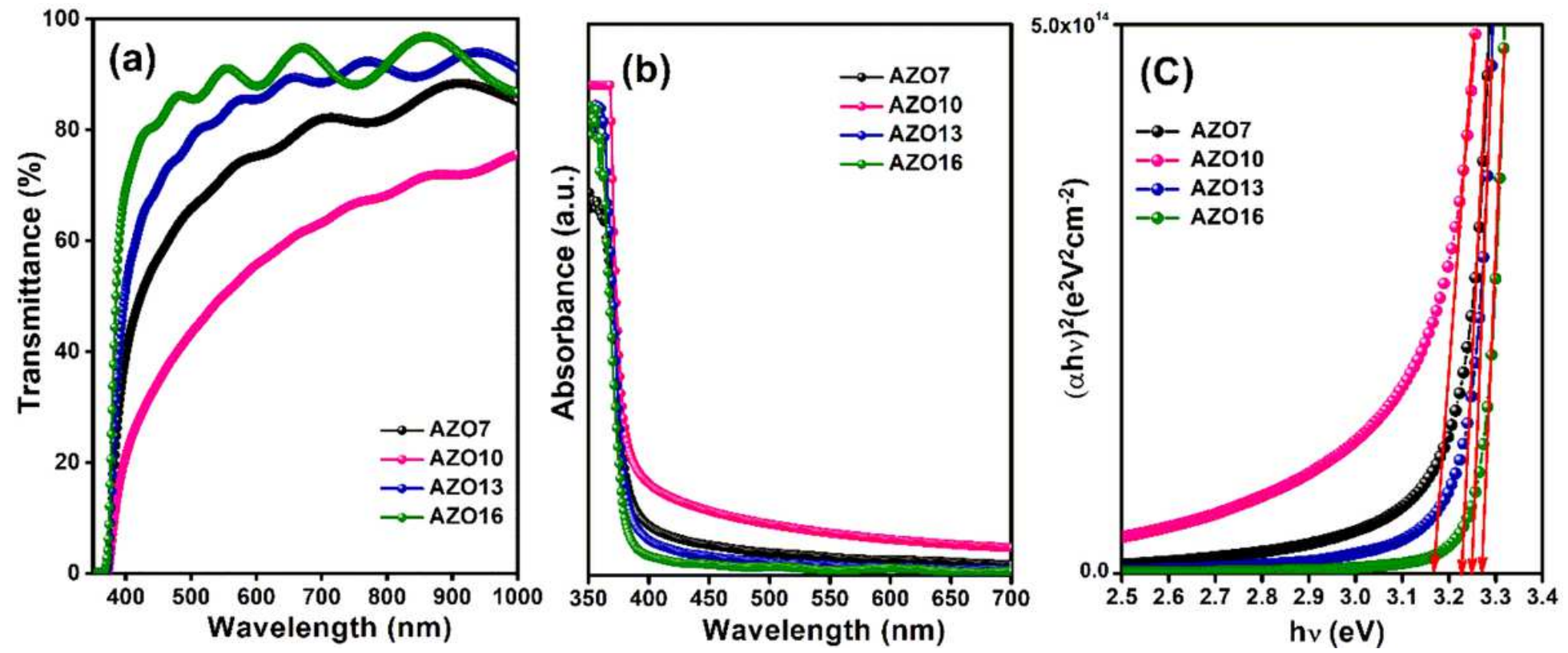

Figure 7 
(a)Transmission spectra (b) absorbance spectra and (c) tauc plots revealing optical band gaps of the AZO samples. 